\title{
Design of Inquiry Learning Process Based on WebQuest
}

\author{
Jun $\mathrm{Ma}^{1, \mathrm{a}^{*}}$ \\ School of Educational Science and Technology, Northwest University for Nationalities, Lanzhou \\ 730000, P.R. China. \\ a364221500@qq.com
}

Keywords: WebQuest; Inquiry learning; Instructional design; Internet environment; Learning model

\begin{abstract}
The article studied mainly the design of inquiry learning process based on WebQuest and the methods of inquiry teaching activities in the process. Firstly, this paper analyzed the technical advantages of Webquest in cultivating learners' innovation and practical capabilities, and then analyzed the drawbacks of the traditional inquiry learning. It summarized the reform of traditional education and the cultivation of learners' practical, manipulating and innovation abilities, and put forward the methods of applying Webquest in the design of inquiry learning process. Finally, the article selected the specific course and applied WebQuest in the actual teaching behavior, and designed the teaching case based on WebQuest.
\end{abstract}

\section{Introduction}

Webquest is an inquiry learning mode based on network application, and in such learning mode, learners take the initiative to learn in the network environment and finally construct beneficial knowledge on the original knowledge foundation. Its emergence makes inquiry learning move one large step forward, guiding and helping learners to analyze specific issues and conduct in-depth exploration and thinking just like professional researchers. I hope the research into this subject can have similar functions as the "staging", making college students divide a huge learning tasks into several subtasks and goals and connect them according to their connections and features instead of being at sea. Once the problem becomes small, students can gain some logic and thoughts, clearly know what to do and conduct subsequent researches following certain thoughts, and finally develop good learning and research habits and thoughts.

\section{Introduction to Webquest}

What is Webquest. Webquest was developed by Dr. Bernie Dodge, etc. and some other education technology teachers from the U.S. San Diego State University. [1] "In the Internet environment and on the premise that teachers determine the learning subject and then assign certain "tasks" focusing the subject in a particular environment to motivate students to make full use of online resources for explorative study. There can be one or more 'tasks'. [2] Webquest is supported by altogether three theories: respectively coordinative learning theory, explorative learning theory and constructive learning theory.

Component Modules of Webquest. Most Webquest in teaching contain the several following parts, showing as Fig. 1.

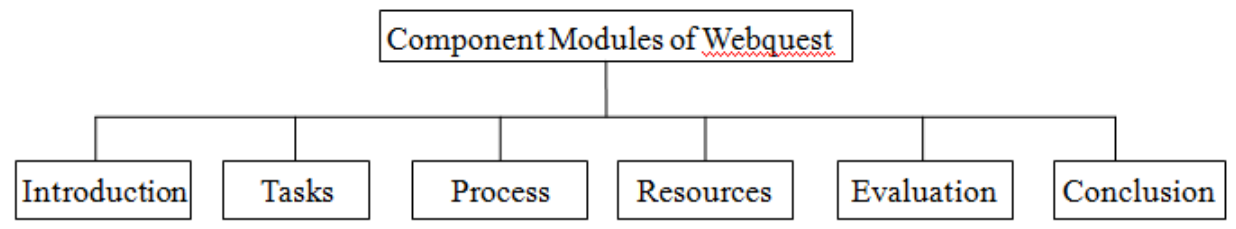

Figure 1. Component Modules of Webquest

Introduction: Creating situation. 
Task: To provide a framework for learners to construct knowledge.

Process: It is the direct basis reflecting the methods used by learners to complete the entire learning tasks and the process.

Resources: Information resources that help learners to complete classroom learning.

Evaluation: evaluation of learners' learning process and final results.

Conclusion: learners' conclusion and reflection.

Webquest's Advantages. Webquest can be divided into two kinds: short-term Webquest and long-term Webquest, [3] and both of the commonly reflect Webquest's three distinguished features:

It has a relatively unified task, which is designed by the teacher before the class and helps teachers to organize the same teaching activities. Webquest provides a "scaffolding" mode, which can guide and help learners to analyze and deeply explore and think about the problems like skilled professional researchers. The "scaffolding" serves to divide problems into several sub-tasks and targets and "construct" them according to certain connections and features. [4] Webquest provides a huge amount of high quality resources that can facilitate learners to save and use them at any time.

Therefore, the teaching mode Webquest is a good transition from traditional classroom learning to entirely open research learning, which can help students to independently choose subjects, freely create and explore in the original form of classroom teaching. [5]

\section{Analysis of Inquiry Learning}

General Procedures of Inquiry Learning. Due to the influence of subject types, course contents, teaching environment and difference between individual learners, different subjects have their corresponding inquiry learning modes. According to most scholars' analysis of inquiry learning process, inquiry learning and teaching are associated with and different from scientific research at five levels, and features of these five aspects also constitute five basic links of inquiry learning. ${ }^{[6]}$ showing as Fig. 2.

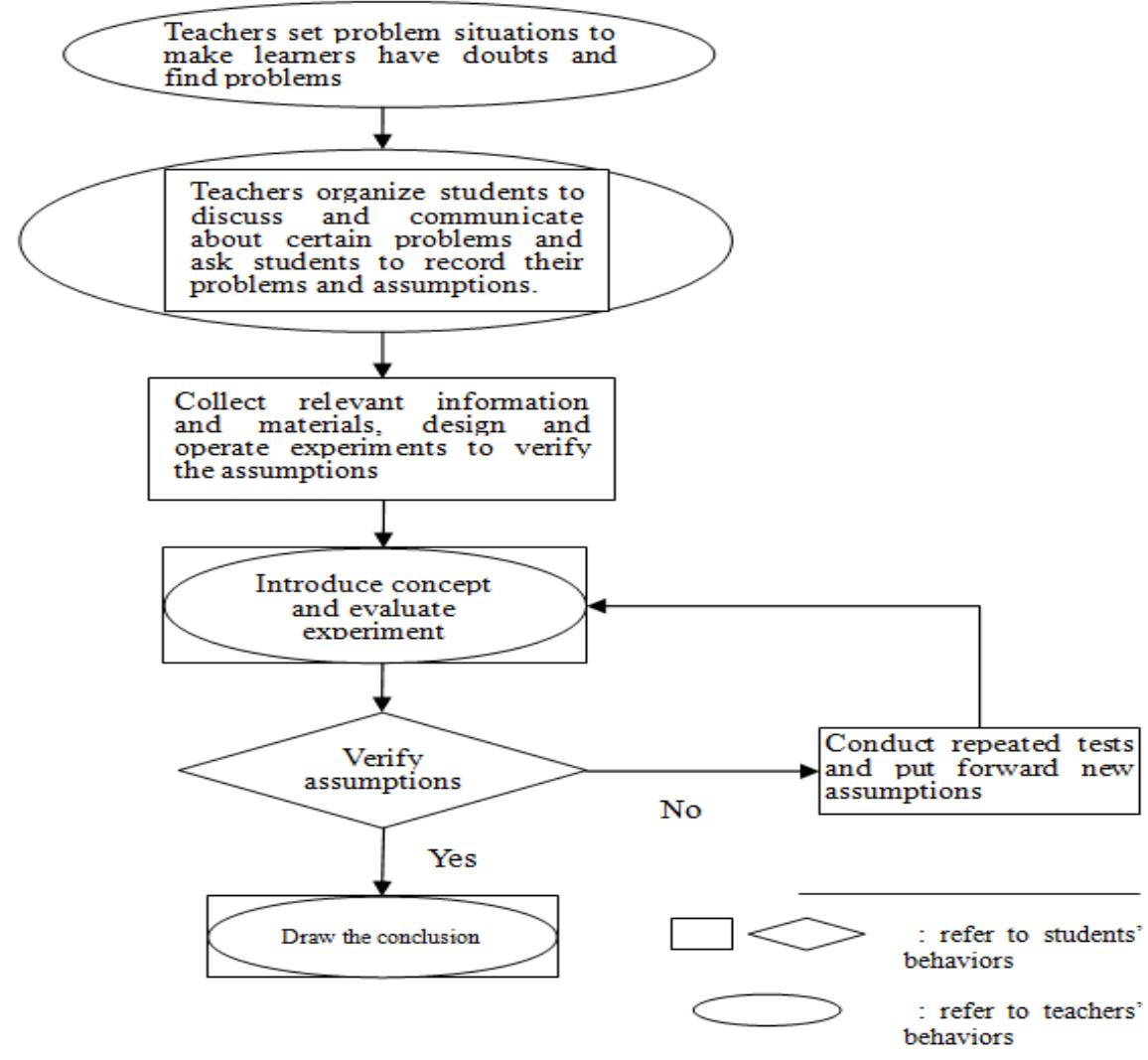

Figure 2. Flow chart of inquiry learning

Put forward problems: focus all students' attention on exploring the teachers' questions.

Collect data: learners collect materials and information used during study. 
Form assumptions: put forward assumptions about the problems encountered.

Validate evaluation: learners test and evaluate their assumptions.

Draw the conclusion: learners communicate with each other and draw the conclusion.

Drawbacks in Traditional Inquiry Learning. The evaluation over-emphasizes results and neglects the process. In the process of inquiry learning, it is a common and long-standing phenomenon to pay too much attention to the conclusion of the research and its processing and presentation, and to pay attention to the social and academic value of the results.

Dislocation of Teachers and Students [7].Some teachers cannot quickly adapt to their new roles in the inquiry learning activities with excessive intervention of learners, and even put forward research problems while designing the situation for learners and formulate research schemes and research methods. Learners cannot become completely independent from teachers both psychologically and in knowledge nor have independent research ability. Students should be the main body of correct inquiry learning while teachers just play a supporting role. Learners conduct independent research under the guidance of teachers. [8]

Teachers lack professional knowledge and cannot provide learners with effective help. Inquiry learning is centered on students, but this is not to say that the main role of teachers in the classroom is weakened, but higher requirements were put forward for the teacher's ability and comprehensive quality. Many problems involved in inquiry learning cannot be solved only by the knowledge and skills of a subject.

Lack of good social and family support. Inquiry learning is strongly interactive and correlative, and such interaction and correlation are embodied not only in the interaction between teachers and learners, but also in interaction between schools, families and the society. However, the current inquiry learning has not yet received good social and family support, and a good atmosphere to support students to participate in social practice has not yet been formed in China. [9]

\section{Advantages of Applying Webquest in Inquiry Learning}

Application of Webquest can Provide Students with High Quality Information. [10] Webquest can provide students with true and reliable information instead of old textbook information, encyclopedia selected by teachers or some moderate magazines. [11] Webquest provides students with high-quality new information through the Internet, thus learners can have more learning resources and better conduct inquiry learning.

Stimulate Learners' Learning Motivation. When teachers design a scene and learners find and propose questions, learners' tasks are real and urgent instead of being solved by teachers' questions due to the virtual tasks of learning knowledge. Through the Internet, learners can directly contact database, experts and the latest information and reports, and they can also email or upload their solutions to make others to evaluate them. [12]

Promote Learners to Have High-Level Thinking. In network inquiry learning activities, to complete tasks assigned by teachers is not merely to make learners answer a single question, but more important, to require them to use more advanced skills to solve the problem, and there thinking skills include comprehension, analysis, creation and judgment. In addition, Webquest creates a learning environment without clear limit, which is of great importance to promote learners' divergent thinking and combines with the traditional teacher, which focuses on cultivating convergent thinking at a certain level and constitutes creative thinking.

Cultivate Learners' Group Learning Ability and Awareness as well as Sense of Teamwork. Webquest teaching mode actively advocates learners to cooperate in the learning process, which cannot only cultivate their explorative spirit, but is also beneficial for learners to have more awareness like cooperation and exchange, thus further improving their inquiry learning awareness and ability. Learners' active engagement, exchange, cooperation and fair games between classmates can also help them have good psychological quality. 


\section{Design Thought}

To apply Webquest in college students' inquiry learning activity is an intermediate type of learning between traditional classroom cramming learning and fully independent learning. We should start from the several following aspects when redesign Webquest teaching plans for college students:

Propose Problems according to Teaching Thoughts. There are four kinds of inquiry learning questions in the network environment: explanatory questions (which require learners to understand the results of resources), inference questions (which require learners to find clues, check clues and discuss which hypothesis is right), hypothetical questions (which are prediction and verification of scientific thinking) and conversion questions (which require learners to have more comprehensive thoughts and transfer the original knowledge to exploration of another question). [13] Any one of the four types comes from real life or the teaching contents of a subject, and to propose questions by combining the two situations is the main source of inquiry questions. On the other hand, the proposed questions should try to be true and can be investigated and studied with significance.

Preparation of Teaching Resources. Network-based education information and resources that can be integrated into teaching process can include teaching materials (such as maps, tables, pictures and articles, etc.), online demonstration (including online demonstration, guidance, audio and video, multimedia, etc.), learning activity and online exploration, etc. In addition, while designing learning resources, we should focus on the learner and pay attention to the creation of situations.

Process of Designing Teaching Activities. The key point of inquiry learning in network environment is inquiry instead of the network. While designing the learning activity, we should first design a good online learning environment, which can increase learning efficiency. Secondly, pay attention to teachers' guiding role in learning. For students' involvement in the learning process and their works, teachers should make timely and non-emotional comments that are in line with facts. Finally, while dividing learning groups, each group should have an appropriate number of members, not too excessive. Meanwhile, we should consider the collocation of each group member's ability. Generally, a complementary way can improve the learning effect.

Evaluation of Course Design. There are several principles in the evaluation of inquiry learning in the network environment, which are scientific principle, feasibility principle, student centered principle and comprehensive principle. The frequently used evaluation methods include learning portfolio, questionnaire, work analysis and classroom observation. In the evaluation, we should try to avoid the constraints of teachers' emotional factors, the individual evaluation should be combined with the group evaluation, and highlight the process evaluation, emphasizing self-reflection evaluation. The way and principle of evaluation can also be carried out with appropriate and scientific changes with different subjects and different teaching contents.

\section{Design Examples of Applying Webquest in Inquiry Learning}

Teaching Theme. In this case, the course "Outline of Chinese Modern History" and "Human Opium Prohibition" are selected.

Teaching Requirements and Form. Subjects: college students. Target: Comprehensively understand and master Lin Zexu's feat of Opium Prohibition" and understand the history of modern China. Teaching Mode: Webquest mode. Webquest Type: short-term. Equipment Requirement: multi-media classroom with network function. Teaching design and presentation mode; PowerPoint manuscript or web.

Process of Designing Teaching. Problem Situation: Government of the Qing Dynasty implemented measures to ban opium, and the Imperial Envoy Lin Zexu destroyed and confiscated opium at Humen, Guangdong in June 1839. [14]

Tasks: According to the theme, there are three tasks, showing as Table 1. 
Table 1 Learning Task Assignment

\begin{tabular}{|c|l|l|}
\hline Task & Task Contents & Research Direction \\
\hline 1 & Lin Zexu's Life & Study Lin Zexu's Life and Anecdotes \\
\hline 2 & $\begin{array}{l}\text { Lin Zexu's smoking-banning } \\
\text { journey }\end{array}$ & Study Lin Zexu's smoking-banning journey \\
\hline 3 & Works of Lin Zexu & Study Lin Zexu's poems, couplets and works \\
\hline
\end{tabular}

Divide the class into several groups, each group containing 4 people, and select a team leader for each group. In addition to completing learning tasks, team leaders are also responsible for team members' division of roles, showing as Table 2.

Table 2 Role distribution and task assignment

\begin{tabular}{|l|l|}
\hline Role & Specific work \\
\hline $\begin{array}{l}\text { Graph and document } \\
\text { collector }\end{array}$ & Responsible for collecting pictures and text materials in the task \\
\hline Audio data collector & Responsible for collecting audio data \\
\hline $\begin{array}{l}\text { Data collector and } \\
\text { editor }\end{array}$ & Gather the collected information and make a manuscript \\
\hline $\begin{array}{l}\text { Result demonstration } \\
\text { personnel }\end{array}$ & Responsible for demonstrating the group's tasks and results \\
\hline
\end{tabular}

Resources: Each team member mainly uses online resources to complete their own learning tasks, such as Table 3.

Table 3 Online resources

\begin{tabular}{|c|c|}
\hline Web type & Website \\
\hline \multirow{6}{*}{$\begin{array}{l}\text { Search } \\
\text { Engine }\end{array}$} & http://baike.so.com/doc/5373456.html \\
\hline & http://www.m1905.com/vod/play/475756.shtml \\
\hline & $\begin{array}{l}\text { http://image.so.com/i?src=imageonebox\&q=\%E6\%9E\%97\%E5\%88\%99 } \\
\% \text { E5\%BE\%90 }\end{array}$ \\
\hline & http://wenda.so.com/q/1363524373060118?src=110 \\
\hline & http://baike.soso.com/v95477.htm \\
\hline & http://www.baike.com/wiki/\%E6\%9E\%97\%E5\%88\%99\%E5\%BE\%90 \\
\hline \multirow{5}{*}{$\begin{array}{l}\text { Normal } \\
\text { Education } \\
\text { Websites }\end{array}$} & $\begin{array}{l}\text { http://www.mzyxlzx.com/html/html/wenyizhuzuo/chuanshuo/2011/0116/1 } \\
\text { 195.html }\end{array}$ \\
\hline & http://www.docin.com/d-86535.html \\
\hline & http://www.docin.com/d-86535.html \\
\hline & http://blog.sina.com.cn/s/blog_3e6806800100n6cn.html \\
\hline & http://www.lsfyw.net/article/html/7528.html \\
\hline
\end{tabular}

In addition, learners can also supplement information from the library and campus website.

Process: Fully understand the learning theme; Divide groups within a class; Learners conduct inquiry-learning from the websites to seek necessary information; Collect information. Demonstrate results.

Evaluation: Group members' attitudes towards inquiry learning; Attitudes towards coordination between group members; Scientific nature for team members to use methods and skills; Team members' innovative spirit is embodied in development of their practical ability; Integration and correctness of the collected information and materials; Logic of demonstrating results and contents; Value and significance of task conclusion; Effect of result demonstration.

Conclusion: Final conclusion of the activity should be jointly summarized by teachers and learners. Teachers summarize the significance of learning this subject and learners summarize 
knowledge learned during the learning process as well as their learning attitudes and methods.

\section{Conclusions}

The application of WebQuest in students' inquiry learning activities provides a good platform for the cultivation of students' active learning ability and collaborative learning ability cultivates their cooperative ability and independent thinking, brings good learning result. Teachers' evaluation of students' learning process and students' self-evaluation, enhances students' subject consciousness, and improves their convergent thinking, and the abilities of collecting and processing information.

\section{Acknowledgements}

The study is funded by "Research on the Management Mode of Open Experimental Teaching Based on Projects" (No: 2014JG-2670030629).

\section{References}

[1]Y.L. He: Research into Application of WebQuest in Primary School Education (MS.D.,Thesis of Capital Normal University, China 2012),p76. (In Chinese).

[2] Z.P. Sun, J.H. Su and S.Q. Chen: Some Thoughts about Inquiry Learning [J].Exploration into Education, Vol.17 (2011) No.5,p44. (In Chinese).

[3] J. Wan: Design and Realization of WebQuest Online Course (MS.D. Thesis of University of Electronic Science and Technology of China, China 2012), P154. (In Chinese).

[4] D.J. Huang: Exploration of Webquest-based English Teaching Modes (Ph.D., Thesis of Central China Normal University, China 2014), p241. (In Chinese).

[5] Z.X. Chi: Research into the Design and Application of Inquiry Learning in Network Environment (Ph.D., Thesis of Shandong Normal University, China 2014),p220. (In Chinese).

[6] Y.Y. Yue: Research into the Application of Knowledge Management in Network Inquiry Learning (Ph.D., Thesis of Shaanxi Normal University, China 2012),p650. (In Chinese).

[7] Information on http://elearning.teacher.com.cn/cms/detail

[8] Y.L. Wang and Y.C. Ban: Role of Teachers' Interferences in Improving Learners' Initiative [J].Journal of School of Foreign Languages, Shandong Normal University, 7(2013):144-150.

[9] Z.Q. Xia: Reflection on Inquiry Learning in Network Environment [J].Education Theory and Practice, Vol.23(2014)No.3,p101. (In Chinese).

[10] Information on http://www.doc88.com/p-997232481769.html

[11] Information on http://www.yxjedu.com/Webquest/web_shuo_ming_x..html

[12] Information on http://wenku.baidu.com/view/2b0156c19ec3d5b

[13] Information on http://www.elab.org.cn

[14] H.F. Li: Outline of Chinese Modern History(.Higher Education Press, Beijing 2013,pp.264-266. (In Chinese). 